\title{
The Utility of Predicting Hospitalizations Among Patients With Heart Failure Using mHealth: Observational Study
}

Susie Cartledge ${ }^{1,2}$, BN (Hons), PhD; Ralph Maddison ${ }^{2}$, BHSc, MSc (Hons), PhD; Sara Vogrin ${ }^{3}$, MBBS, MBiostat; Roman Falls ${ }^{3}$, BPharmSc; Odgerel Tumur ${ }^{3}$, MBBS, PhD; Ingrid Hopper ${ }^{4}$, MBBS, PhD; Christopher Neil ${ }^{3,5}$, MBBS, $\mathrm{PhD}$

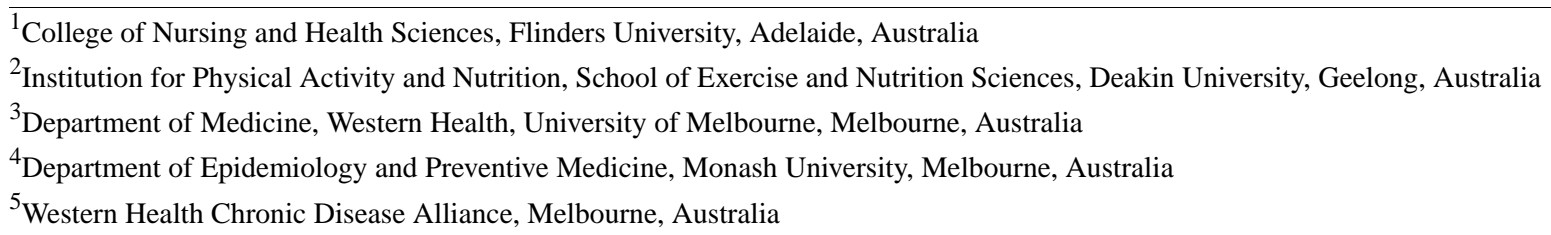

\section{Corresponding Author:}

Susie Cartledge, BN (Hons), PhD

Institution for Physical Activity and Nutrition

School of Exercise and Nutrition Sciences

Deakin University

Locked Bag 20000

Geelong, 3220

Australia

Phone: 61438263164

Email: susie.cartledge@deakin.edu.au

\section{Abstract}

Background: Heart failure decompensation is a major driver of hospitalizations and represents a significant burden to the health care system. Identifying those at greatest risk of admission can allow for targeted interventions to reduce this risk.

Objective: This paper aims to compare the predictive value of objective and subjective heart failure respiratory symptoms on imminent heart failure decompensation and subsequent hospitalization within a 30-day period.

Methods: A prospective observational pilot study was conducted. People living at home with heart failure were recruited from a single-center heart failure outpatient clinic. Objective (blood pressure, heart rate, weight, B-type natriuretic peptide) and subjective (4 heart failure respiratory symptoms scored for severity on a 5-point Likert scale) data were collected twice weekly for a 30-day period.

Results: A total of 29 participants (median age 79 years; 18/29, 62\% men) completed the study. During the study period, 10 of the 29 participants (34\%) were hospitalized as a result of heart failure. For objective data, only heart rate exhibited a between-group difference. However, it was nonsignificant for variability $(P=.71)$. Subjective symptom scores provided better prediction. Specifically, the highest precision of heart failure hospitalization was observed when patients with heart failure experienced severe dyspnea, orthopnea, and bendopnea on any given day (area under the curve of 0.77 ; sensitivity of $83 \%$; specificity of $73 \%)$.

Conclusions: The use of subjective respiratory symptom reporting on a 5-point Likert scale may facilitate a simple and low-cost method of predicting heart failure decompensation and imminent hospitalization. Serial collection of symptom data could be augmented using ecological momentary assessment of self-reported symptoms within a mobile health monitoring strategy for patients at high risk for heart failure decompensation.

(JMIR Mhealth Uhealth 2020;8(12):e18496) doi: $\underline{10.2196 / 18496}$

\section{KEYWORDS}

cardiac failure; heart failure; readmission; hospitalization; risk prediction; mHealth 


\section{Introduction}

Heart failure (HF) is a complex, chronic, and debilitating cardiac condition currently estimated to affect 38 million people internationally [1]. In Australia, 2014 prevalence estimates indicated that there were 480,000 adults living with $\mathrm{HF}$, which represents $2.1 \%$ of the Australian population, with the prevalence forecast to significantly increase [2]. HF is caused by the inability of the heart to fill and eject sufficient blood to meet bodily demands, resulting in symptoms such as dyspnea, fatigue, and palpitations [3]. The exacerbation of HF symptoms, representing HF decompensation, is a major driver of hospitalization rates. HF hospitalizations represent a significant proportion of the total expenditure for HF in Australia annually [2]. Therefore, monitoring HF symptoms is essential in order to identify and prevent potential $\mathrm{HF}$ decompensation and subsequent hospitalization.

Collaboration between people living with $\mathrm{HF}$ and health care professionals (eg, heart failure nurses) is critical for monitoring HF symptoms and potential exacerbations [4]. While there are smartphone apps that focus on symptom monitoring, none currently provide risk prediction [4]. While HF mortality can be predicted with reasonable accuracy $[5,6]$, risk prediction for HF hospitalization has demonstrated only modest performance in models reported to date. Variables used in HF risk predication models have included, in isolation or in combination [7], administrative data (such as Medicare claims data) [8], patient characteristics, clinical data, and geomapping [9]. However, the quantitation of self-reported subjective symptoms as an early indication of decline and therefore risk has on the whole been overlooked. Therefore, the aim of this study was to compare the predictive value of objectively and subjectively measured HF respiratory symptoms on imminent HF decompensation and subsequent hospitalization within a 30-day period.

\section{Methods}

\section{Study Design, Setting, and Participants}

We conducted a prospective observational pilot study with participants identified via cardiologist assessment as being at high risk of a HF hospitalization. Participants were recruited from a single-center HF outpatient clinic within a tertiary hospital in Melbourne, Australia. Eligible participants were older than 18 years, had a physician-documented HF diagnosis, had a previous hospital admission for HF exacerbation, were on maximum tolerated pharmacotherapy, and were able to read and understand English. Exclusion criteria included severe HF symptoms (New York Heart Association Class IV), advanced malignancy, cognitive impairment, and use of end-of-life care. This study was approved by the Western Health Human Research Ethics Committee (2016.071).

\section{Measures}

Participants were visited twice weekly by a research assistant (one a biomedical science graduate the other a medical doctor) for a 30-day period from June 2016 to May 2017. The research assistants collected all measurements, including the subjective respiratory scores, from patients. Study data and sources are described in Table 1.

Table 1. Variables collected during study period and associated data sources.

\begin{tabular}{ll}
\hline Variables & Data source \\
\hline Objective measures & \\
Blood pressure & Validated study sphygmomanometer \\
Heart rate & Manual pulse \\
Weight & Validated study scales \\
B-type natriuretic peptide & Point-of-care testing \\
Subjective measures & \\
Dyspnea & 5-point Likert scale \\
Bendopnea & 5-point Likert scale \\
Orthopnea & 5-point Likert scale \\
Paroxysmal nocturnal dyspnea & 5-point Likert scale \\
Other variables & \\
Demographics & Medical record and participant survey \\
Medical history & Medical record \\
Hospitalization status & Medical record \\
\hline
\end{tabular}

${ }^{\mathrm{a}} 1$ indicates no symptoms and 5 indicates severe symptoms.

Subjective symptoms of dyspnea, orthopnea, bendopnea, and paroxysmal nocturnal dyspnea (PND) were chosen because they are routinely used indicators of clinical status in HF, each of which feature in 2 key diagnosis criteria [10,11]. Likert scales to instantaneously quantify dyspnea in HF populations have been researched using 7- and 5-point scales [12,13]. 
Additionally, the 5-point Likert scale-quantified dyspnea has previously demonstrated a relationship with subsequent emergency readmission [13].

\section{Statistical Analysis}

Given that this is a pilot study, no formal power calculations were undertaken. Baseline characteristics are presented as median (interquartile range) or frequency (percentage) and are compared between hospitalized and nonhospitalized patients using a rank sum test and Fisher exact test.

To assess whether objective measures (blood pressure, heart rate $[\mathrm{HR}]$, variation in $\mathrm{HR}$, weight, and B-type natriuretic peptide [BNP]) were associated with hospitalization, their mean value, standard deviation, and slope of change were calculated over 7 days prior to hospitalization (for admitted patients) and over the whole observation period for others (with at least 7 days' clearance before and after any hospitalization). These were then compared using a rank sum test. The same technique was applied using a symptom severity score, and their variability was compared by calculating a median score and range of scores.

To determine the optimal severity cutoff value on the Likert scale for each respective symptom, a random day within the 7 days prior to hospitalization (for hospitalized patients) and any random day for others was chosen. The area under the receiver operating characteristics curve (AUC) and the Youden index (YI) were calculated. This process was repeated 1000 times with different combinations of random days. The cutoff value with the most frequent highest AUC and Youden index was chosen. This cutoff was then used for all analyses.
To determine which combination of symptoms best predicted hospitalization, we calculated AUC, YI, sensitivity, and specificity and compared them among all combinations of symptoms (eg, bendopnea and orthopnea, bendopnea and dyspnea, bendopnea and dyspnea and orthopnea-a total of 10 possible combinations) on 1000 combinations of randomly chosen days (as described above). In the next step, 2 random consecutive symptom measurements (usually 2 to 3 days apart) were chosen, and we determined the ability to predict hospitalization if the symptom was severe on either day or both days or if the symptom severity increased across the 2 days. This was performed separately for each symptom and for all 10 combinations of symptoms (as described above). Sensitivity, specificity, AUC, and YI were calculated. All analyses were performed using Stata 15.1 (StataCorp).

\section{Results}

\section{Baseline Population Characteristics}

A total of 30 participants met the study inclusion criteria and provided written informed consent; however, one participant withdrew from the study shortly after enrollment. During the study, 10 of the 29 participants (34\%) were hospitalized as a result of decompensated $\mathrm{HF}$, as adjudicated by the Boston criteria on file review (the comparator group). Another participant was admitted for infection without congestion.

As demonstrated in Table 2, the participants who were hospitalized had higher left ventricular ejection fractions but worse baseline Minnesota Living With HF scores and were on less angiotensin- converting enzyme inhibitors and angiotensin II receptor blocker therapies. 
Table 2. Baseline demographics and comparison by heart failure hospitalization.

\begin{tabular}{|c|c|c|c|c|}
\hline Characteristic & All participants $(\mathrm{N}=29)$ & Not hospitalized $(19 / 29,66 \%)$ & Hospitalized $(10 / 29,34 \%)$ & $P$ value \\
\hline Age (years), median (IQR) & $79(69-84)$ & $74(68-82)$ & $81.5(73-89)$ & .12 \\
\hline Sex, n (\%) & & & & .69 \\
\hline Male & $18(62)$ & $11(58)$ & $7(70)$ & \\
\hline Female & $11(38)$ & $8(42)$ & $3(30)$ & \\
\hline Ethnic group, n (\%) & & & & .56 \\
\hline Non-Indigenous Australian & $7(24)$ & $6(32)$ & $1(10)$ & \\
\hline European & $8(28)$ & $5(26)$ & $3(30)$ & \\
\hline Indian & $1(3)$ & $1(5)$ & $0(0)$ & \\
\hline Pacific Islander & $5(17)$ & $2(11)$ & $3(30)$ & \\
\hline Other & $8(28)$ & $5(26)$ & $3(30)$ & \\
\hline Born in Australia, n (\%) & $11(39)$ & $9(47)$ & $2(22)$ & .25 \\
\hline Education, n (\%) & & & & .12 \\
\hline Some high school & $19(66)$ & $15(79)$ & $4(40)$ & \\
\hline Trade certificate & $8(28)$ & $4(21)$ & $4(40)$ & \\
\hline Some university & $2(7)$ & $0(0)$ & $2(20)$ & \\
\hline Work status, n (\%) & & & & .69 \\
\hline Part-time & $1(3)$ & $1(5)$ & $0(0)$ & \\
\hline Full-time & $2(7)$ & $2(11)$ & $0(0)$ & \\
\hline Retired & $26(90)$ & $16(84)$ & $10(100)$ & \\
\hline Household income (Aus \$) $)^{\mathrm{a}}, \mathrm{n}(\%)$ & & & & .40 \\
\hline$<20,000$ & $18(62)$ & $10(53)$ & $8(80)$ & \\
\hline $20,000-30,000$ & $10(34)$ & $8(42)$ & $2(20)$ & \\
\hline $30,000-40,000$ & $1(3)$ & $1(5)$ & $0(0)$ & \\
\hline Years since $\mathrm{HF}^{\mathrm{b}}$ diagnosis, $\mathrm{n}(\%)$ & & & & .42 \\
\hline$\leq 5$ years & $18(62)$ & $13(68)$ & $5(50)$ & \\
\hline $5-10$ years & $4(14)$ & $3(16)$ & $1(10)$ & \\
\hline $10-20$ years & $5(17)$ & $2(11)$ & $3(30)$ & \\
\hline$>20$ years & $2(7)$ & $1(5)$ & $1(10)$ & \\
\hline $\mathrm{HFrEF}^{\mathrm{c}}, \mathrm{n}(\%)$ & $16(55)$ & $12(63)$ & $4(40)$ & .27 \\
\hline Baseline NYHA $^{\mathbf{d}}, \mathbf{n}(\%)$ & & & & .09 \\
\hline NYHA II & $10(34)$ & $9(47)$ & $1(10)$ & \\
\hline NYHA III & $19(66)$ & $10(53)$ & $9(90)$ & \\
\hline $\mathrm{LVEF}^{\mathrm{e}}$, median (IQR) & $35(28-50)$ & $30(22-46)$ & $50(35-57)$ & .02 \\
\hline $\begin{array}{l}\text { Baseline Minnesota Living With HF } \\
\text { score }^{f} \text {, median (IQR) }\end{array}$ & $58(48-70)$ & $53(40-62)$ & $72.5(54-81)$ & .02 \\
\hline $\begin{array}{l}\text { HF hospitalization in previous } 6 \\
\text { months, } \mathrm{n}(\%)\end{array}$ & $25(86)$ & $17(89)$ & $8(80)$ & .59 \\
\hline $\begin{array}{l}\text { Emergency department attendance in } \\
\text { previous } 12 \text { months, } \mathrm{n}(\%)\end{array}$ & $21(75)$ & $13(68)$ & $8(89)$ & .37 \\
\hline Body mass index, median (IQR) & $30.42(25.65-38.72)$ & $30.80(25.65-39.82)$ & $30.27(25.13-32.25)$ & .65 \\
\hline \multicolumn{5}{|l|}{ Medical history, n (\%) } \\
\hline Hypertension & $27(93)$ & $17(89)$ & $10(100)$ & .53 \\
\hline
\end{tabular}




\begin{tabular}{|c|c|c|c|c|}
\hline Characteristic & All participants $(\mathrm{N}=29)$ & Not hospitalized $(19 / 29,66 \%)$ & Hospitalized $(10 / 29,34 \%)$ & $P$ value \\
\hline Ischemic heart disease & $16(55)$ & $10(53)$ & $6(60)$ & $>.99$ \\
\hline Hypercholesterolemia & $22(76)$ & $16(84)$ & $6(60)$ & .19 \\
\hline Atrial fibrillation & $19(66)$ & $11(58)$ & $8(80)$ & .41 \\
\hline Cerebrovascular accident & $7(24)$ & $6(32)$ & $1(10)$ & .37 \\
\hline Diabetes mellitus & $17(59)$ & $10(53)$ & $7(70)$ & .45 \\
\hline $\mathrm{COPD}^{\mathrm{g}}$ or asthma & $11(38)$ & $6(32)$ & $5(50)$ & .43 \\
\hline \multicolumn{5}{|l|}{ Use of therapies } \\
\hline Loop diuretic, $\mathrm{n}(\%)$ & $27(93)$ & $17(89)$ & $10(100)$ & .53 \\
\hline $\begin{array}{l}\text { Daily loop diuretic dose, median } \\
\text { (IQR) }\end{array}$ & $80(80-120)$ & $80(40-80)$ & $100(80-60)$ & .09 \\
\hline$\beta$ blocker, n (\%) & $26(90)$ & $17(89)$ & $9(90)$ & $>.99$ \\
\hline $\mathrm{ACE}^{\mathrm{h}}{ }^{\mathrm{h}}$ or $\mathrm{ARB}^{\mathrm{i}}, \mathrm{n}(\%)$ & $22(76)$ & $17(89)$ & $5(50)$ & .03 \\
\hline Aldosterone antagonist, $\mathrm{n}(\%)$ & $12(41)$ & $8(42)$ & $4(40)$ & $>.99$ \\
\hline
\end{tabular}

${ }^{\mathrm{a}}$ At the time of publication, a currency exchange rate of Aus $\$ 1=$ US $\$ 0.74$ was applicable.

${ }^{\mathrm{b}} \mathrm{HF}$ : heart failure.

${ }^{\mathrm{c}} \mathrm{HFrEF}$ : heart failure with reduced ejection fraction.

${ }^{\mathrm{d}}$ NYHA: New York Heart Association.

${ }^{\mathrm{e}} \mathrm{LVEF}$ : left ventricular ejection fraction.

${ }^{f}$ The Minnesota Living With Heart Failure scoring range is from 0 to 105, with higher scores indicating poorer health-related quality of life.

${ }^{\mathrm{g}} \mathrm{COPD}$ : chronic obstructive pulmonary disease.

${ }^{\mathrm{h}} \mathrm{ACE}-\mathrm{I}$ : angiotensin-converting enzyme inhibitor.

${ }^{\mathrm{i}} \mathrm{ARB}$ : angiotensin II receptor blocker.

\section{Objective Measures}

Of the 4 objective measures collected, only HR demonstrated a significant difference between groups (median 80 vs 67 beats per minute $[\mathrm{bpm}] ; P=.02$ ) (Table 3 ). Variation in HR over the study period, however, was nonsignificant between groups (7 vs $6 \mathrm{bpm} ; P=.71)$. Participants admitted to the hospital demonstrated higher BNP values (median 1113 vs $546 \mathrm{pg} / \mathrm{mL}$; $P=.09$ ), with a higher average daily increase prior to hospitalization (20 vs $0.05 \mathrm{pg} / \mathrm{mL} / \mathrm{d} ; P=.08)$. 
Table 3. Objective and subjective measures.

\begin{tabular}{|c|c|c|c|}
\hline Measures & Not hospitalized, median (IQR), $(\mathrm{n}=19)$ & Hospitalized, median (IQR), $(\mathrm{n}=10)$ & $P$ value \\
\hline \multicolumn{4}{|l|}{ Objective measures } \\
\hline \multicolumn{4}{|l|}{ Weight } \\
\hline Average $(\mathrm{kg})$ & $87(73.8$ to 95.6$)$ & 84.5 (64 to 96.1$)$ & .52 \\
\hline Variability (standard deviation) $(\mathrm{kg})$ & $0.97(0.63$ to 1.30$)$ & 1.07 (0.61 to 2.86$)$ & .57 \\
\hline Slope (kg/d) & $0.00(-0.04$ to 0.02$)$ & $0.13(-0.15$ to 0.33$)$ & .26 \\
\hline \multicolumn{4}{|l|}{ Systolic blood pressure } \\
\hline Average (mmHg) & 121.8 (108 to 128.7$)$ & $123.2(113.8$ to 131.7$)$ & .65 \\
\hline Variability (standard deviation) (mmHg) & $12.8(8.3$ to 15.4$)$ & $15.4(11.1$ to 17.6$)$ & .29 \\
\hline Slope $(\mathrm{mmHg} / \mathrm{d})$ & $0.25(-0.37$ to 0.64$)$ & $1.06(-0.82$ to 10.5$)$ & .31 \\
\hline \multicolumn{4}{|l|}{ Heart rate } \\
\hline Average $\left(\mathrm{bpm}^{\mathrm{a}}\right)$ & $67.4(62.0$ to 76.2$)$ & $80.4(74.3$ to 88.0$)$ & .02 \\
\hline Variability (standard deviation) (bpm) & $7.5(4.3$ to 10.0$)$ & $7.2(3.6$ to 14.4$)$ & .71 \\
\hline Slope (bpm/d) & $-0.04(-0.17$ to 0.36$)$ & $-0.61(-1.59$ to 0.87$)$ & .38 \\
\hline \multicolumn{4}{|l|}{ B-type natriuretic peptide } \\
\hline Average $(\mathrm{pg} / \mathrm{mL})$ & 545.6 (237.4 to 891.7$)$ & $1112.5(554.5$ to 1565$)$ & .09 \\
\hline Variability (standard deviation) (pg/mL) & 99.9 (47.5 to 231.9$)$ & $164.4(75.2$ to 186.71$)$ & .83 \\
\hline Slope $(\mathrm{pg} / \mathrm{mL} / \mathrm{d})$ & $0.05(-4.85$ to 5.81$)$ & 19.65 (4 to 41.45$)$ & .08 \\
\hline \multicolumn{4}{|l|}{ Subjective measures ${ }^{b}$} \\
\hline \multicolumn{4}{|l|}{ Dyspnea } \\
\hline Median symptom scores & $2(1$ to 3$)$ & $4(3$ to 4$)$ & .009 \\
\hline Ranges in symptom score & $2(1$ to 3$)$ & $0(0$ to 1$)$ & .003 \\
\hline \multicolumn{4}{|l|}{ Orthopnea } \\
\hline Median symptom scores & $1(1$ to 2$)$ & 3.3 (2 to 4$)$ & .007 \\
\hline Ranges in symptom score & $1(0$ to 2$)$ & $0.5(0$ to 1$)$ & .22 \\
\hline \multicolumn{4}{|l|}{ Bendopnea } \\
\hline Median symptom scores & $2(1$ to 3$)$ & $4(3.5$ to 5$)$ & .007 \\
\hline Ranges in symptom score & $2(1$ to 3$)$ & $0(0$ to 1$)$ & .006 \\
\hline \multicolumn{4}{|l|}{ Paroxysmal nocturnal dyspnea } \\
\hline Median symptom scores & 1 (1 to 2$)$ & $3(1.5$ to 4$)$ & .009 \\
\hline Ranges in symptom score & $1(1$ to 3$)$ & $0(0$ to 1$)$ & .004 \\
\hline
\end{tabular}

abpm: beats per minute.

${ }^{b}$ For subjective measures, the median is the median and IQR of the participants' median scores. Range is the median and IQR of participants' range of scores; for example, if the range was 1, that patient had a symptom of 3 and 4 only.

\section{Subjective Measures}

Symptom scores were examined, with hospitalized patients reporting higher median dyspnea, bendopnea, and PND with a lower 7-day range, implying consistently worse symptoms (all $P<.01$ ) (Table 3). Figure 1 shows the symptom measurements experienced at each severity level of the Likert scale. Orthopnea was worse in the HF hospitalization group $(P=.01)$ but had similar variability $(P=.22)$. A symptom score of at least 3 for dyspnea, 2 for orthopnea, and 4 for PND and bendopnea produced the highest AUC and YI for predicting $\mathrm{HF}$ hospitalization. Figure 2 shows the areas under the curve for respiratory symptoms. 
Figure 1. Subjective symptom measurements experienced at each severity level of the Likert scale, showing the weighting of severity in the hospitalized versus nonhospitalized group.
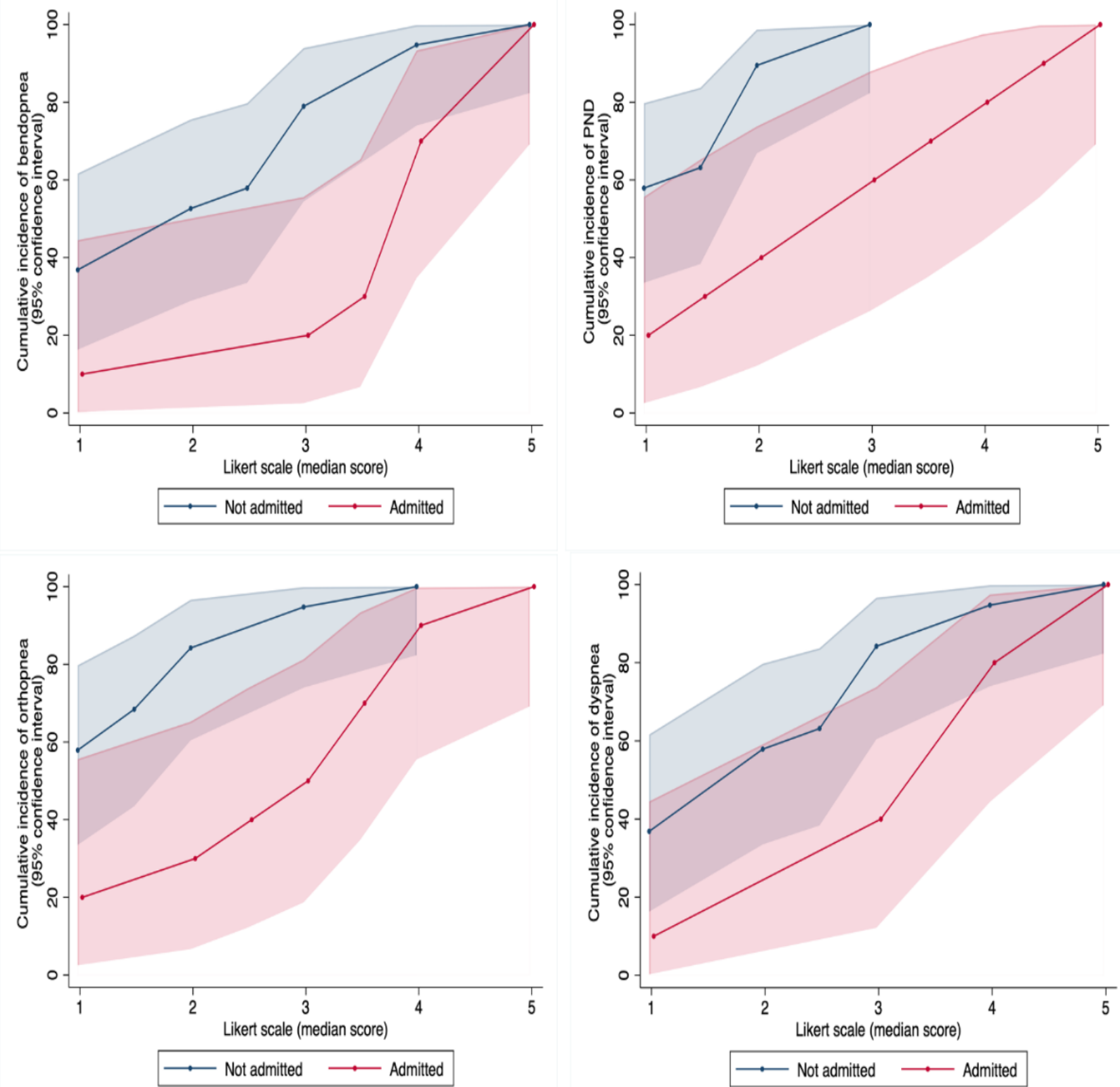
Figure 2. Areas under the curve for subjective respiratory symptoms. AUC: area under the curve.

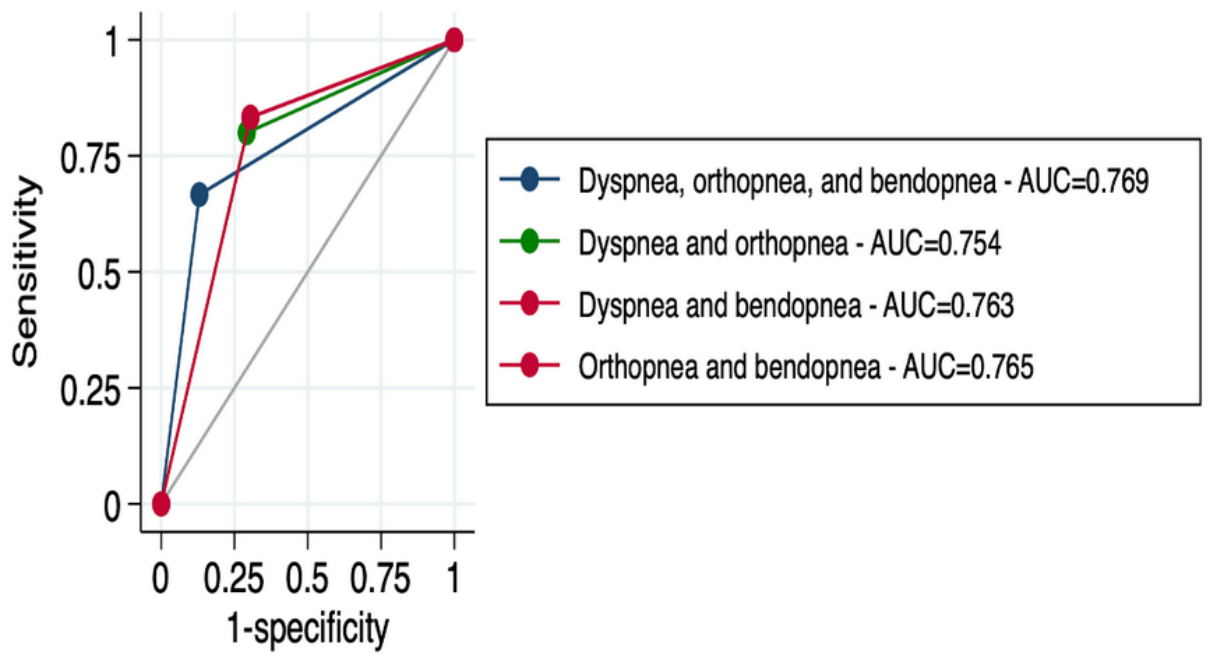

The highest YI (0.54) and AUC (0.77) were observed when on any given day dyspnea, orthopnea, and bendopnea symptoms were severe. This combination predicted hospitalization with a sensitivity of $81 \%$ and a specificity of $73 \%$. Similar results were observed when at least orthopnea and bendopnea were severe (YI=0.53; AUC=0.76; sensitivity of $81 \%$; specificity of $73 \%$ ). Higher sensitivities but lower specificities were observed when dyspnea and bendopnea ( $84 \%$ and $68 \%$, respectively) or dyspnea and orthopnea ( $87 \%$ and $64 \%$, respectively) were severe (see Multimedia Appendix 1 for graphical representation). All other combinations resulted in a YI $<0.50$ and an AUC $<0.75$.

\section{Discussion}

\section{Principal Findings}

In this analysis of the prediction of decompensation and HF hospitalization within 30 days, we demonstrated that compared with objective measures, a simplified system for quantifying respiratory symptom status may be an accurate and useful predictor. Specifically, the highest precision of $\mathrm{HF}$ hospitalization was observed when patients with HF experienced severe dyspnea, orthopnea, and bendopnea on any given day (AUC $=0.77$; sensitivity of $83 \%$; specificity of $73 \%$ ). Early detection of deterioration would allow the care team to provide agile HF care that may be able to prevent subsequent hospital admission.

The lack of a sound risk prediction tool for imminent HF hospitalization makes organization and prioritization of $\mathrm{HF}$ care challenging [5]. Current Australian HF guidelines call for systems of care with an "alert system to flag patients who are displaying signs of clinical deterioration and pathways for rapid medical review" [3]. Given that subjective data outperformed objective data in this pilot cohort, there are opportunities for patients to be able to regularly log respiratory symptoms. This eliminates the need for patients to regularly use medical equipment (eg, sphygmomanometer, scales) to collect prediction data.

Real-time regular data collection of a participant's state, such as HF symptoms, can be conducted through ecological momentary assessment (EMA) [14]. This method allows a picture to be formed of a participant's symptoms, reducing recall bias. EMA data are best collected by electronic means, such as mobile and wireless devices (mobile health [mHealth]), to ensure easy, timely, and compliant documentation [14,15].

The ease of collection of EMA self-reported respiratory symptom data via mHealth could lead to large data sets for analysis. Artificial intelligence and machine learning are increasingly being used to provide clinically meaningful predictive data analysis, especially with large data sets [16]. This technique can be applied to build automated clinical decision systems for problems such as hospitalization risk [16].

\section{Limitations}

The main limitation of this pilot study is its sample size and length of follow-up. The small sample size may affect the variability of some measures (eg, weight), and this should be addressed in future larger trials over a longer period. Future studies could establish baseline respiratory symptoms for patients and examine the timeline of changes in the severity of symptoms and of hospitalization. Additionally, there was selection bias, as patients were recruited from a single-center HF clinic, and this may not represent a typical HF population.

However, unlike previous studies using patients drawn from clinical trials [17], our patients were recruited from standard practice, which may increase the generalizability of the study. Another strength is the use of primary data collected during the study rather than secondary data, such as trial databases, registries, and administrative claims data, which have been used in other studies.

\section{Conclusions}

The use of patient-reported serial quantification of 4 key respiratory HF symptoms (dyspnea, bendopnea, orthopnea, and PND) may provide low-cost detection of imminent decompensation and therefore potential hospitalization. Future research should focus on testing and validating this model with a larger sample, augmenting the findings using an EMA of self-reported HF symptoms via mHealth, and using artificial intelligence data analysis techniques to increase risk prediction accuracy. 


\section{Acknowledgments}

We would like to acknowledge the work of Tarveen Singh, Andrew Mulligan, and Abduwaysi Amie, who assisted with the data collection for this study.

\section{Conflicts of Interest}

None declared.

\section{Multimedia Appendix 1}

Supplementary figures.

[DOCX File, $401 \mathrm{~KB}-$ Multimedia Appendix 1]

\section{References}

1. Vos T, Flaxman A, Naghavi M, Lozano R, Michaud C, Ezzati M, et al. Years lived with disability (YLDs) for 1160 sequelae of 289 diseases and injuries 1990-2010: a systematic analysis for the Global Burden of Disease Study 2010. Lancet 2012 Dec 15;380(9859):2163-2196 [FREE Full text] [doi: 10.1016/S0140-6736(12)61729-2] [Medline: 23245607]

2. Chan Y, Tuttle C, Ball J, Teng TK, Ahamed Y, Carrington MJ, et al. Current and projected burden of heart failure in the Australian adult population: a substantive but still ill-defined major health issue. BMC Health Serv Res 2016 Sep 21;16(1):501 [FREE Full text] [doi: 10.1186/s12913-016-1748-0] [Medline: 27654659]

3. NHFA CSANZ Heart Failure Guidelines Working Group, Atherton JJ, Sindone A, De Pasquale CG, Driscoll A, MacDonald PS, et al. National Heart Foundation of Australia and Cardiac Society of Australia and New Zealand: Guidelines for the Prevention, Detection, and Management of Heart Failure in Australia 2018. Heart Lung Circ 2018 Oct;27(10):1123-1208 [FREE Full text] [doi: 10.1016/j.hlc.2018.06.1042] [Medline: 30077227]

4. Masterson Creber RM, Maurer MS, Reading M, Hiraldo G, Hickey KT, Iribarren S. Review and Analysis of Existing Mobile Phone Apps to Support Heart Failure Symptom Monitoring and Self-Care Management Using the Mobile Application Rating Scale (MARS). JMIR Mhealth Uhealth 2016 Jun 14;4(2):e74 [FREE Full text] [doi: 10.2196/mhealth.5882] [Medline: $\underline{27302310]}$

5. Rahimi K, Bennett D, Conrad N, Williams TM, Basu J, Dwight J, et al. Risk prediction in patients with heart failure: a systematic review and analysis. JACC Heart Fail 2014 Oct;2(5):440-446 [FREE Full text] [doi: 10.1016/j.jchf.2014.04.008] [Medline: 25194291]

6. Levy WC, Mozaffarian D, Linker DT, Sutradhar SC, Anker SD, Cropp AB, et al. The Seattle Heart Failure Model. Circulation 2006 Mar 21;113(11):1424-1433. [doi: 10.1161/circulationaha.105.584102] [Medline: 16534009]

7. Ross JS, Mulvey GK, Stauffer B, Patlolla V, Bernheim SM, Keenan PS, et al. Statistical models and patient predictors of readmission for heart failure: a systematic review. Arch Intern Med 2008 Jul 14;168(13):1371-1386. [doi:

10.1001/archinte.168.13.1371] [Medline: 18625917]

8. Keenan PS, Normand ST, Lin Z, Drye EE, Bhat KR, Ross JS, et al. An administrative claims measure suitable for profiling hospital performance on the basis of 30-day all-cause readmission rates among patients with heart failure. Circ Cardiovasc Qual Outcomes 2008 Sep;1(1):29-37. [doi: 10.1161/CIRCOUTCOMES.108.802686] [Medline: 20031785]

9. Huynh QL, Saito M, Blizzard CL, Eskandari M, Johnson B, Adabi G, MARATHON Investigators. Roles of nonclinical and clinical data in prediction of 30-day rehospitalization or death among heart failure patients. J Card Fail 2015 May;21(5):374-381. [doi: 10.1016/j.cardfail.2015.02.002] [Medline: 25724302]

10. McKee PA, Castelli WP, McNamara PM, Kannel WB. The natural history of congestive heart failure: the Framingham study. N Engl J Med 1971 Dec 23;285(26):1441-1446. [doi: 10.1056/NEJM197112232852601] [Medline: 5122894]

11. Carlson KJ, Lee DC, Goroll AH, Leahy M, Johnson RA. An analysis of physicians' reasons for prescribing long-term digitalis therapy in outpatients. J Chronic Dis 1985;38(9):733-739. [doi: 10.1016/0021-9681(85)90115-8] [Medline: 4030999]

12. Solomonica A, Burger AJ, Aronson D. Hemodynamic Determinants of Dyspnea Improvement in Acute Decompensated Heart Failure. Circ Heart Fail 2013 Jan;6(1):53-60. [doi: 10.1161/circheartfailure.112.970335] [Medline: 23152491]

13. Weber C, Miglioranza M, Moraes M, Sant'anna RT, Rover M, Kalil R, et al. The five-point Likert scale for dyspnea can properly assess the degree of pulmonary congestion and predict adverse events in heart failure outpatients. Clinics (Sao Paulo) 2014;69(5):341-346 [FREE Full text] [doi: 10.6061/clinics/2014(05)08] [Medline: 24838900]

14. Shiffman S, Stone AA, Hufford MR. Ecological momentary assessment. Annu Rev Clin Psychol 2008;4:1-32. [doi: 10.1146/annurev.clinpsy.3.022806.091415] [Medline: 18509902]

15. Whittaker R, Merry S, Dorey E, Maddison R. A development and evaluation process for mHealth interventions: examples from New Zealand. J Health Commun 2012 May;17(Suppl 1):11-21. [doi: 10.1080/10810730.2011.649103] [Medline: 22548594] 
16. Krittanawong C, Zhang H, Wang Z, Aydar M, Kitai T. Artificial Intelligence in Precision Cardiovascular Medicine. J Am Coll Cardiol 2017 May 30;69(21):2657-2664 [FREE Full text] [doi: 10.1016/j.jacc.2017.03.571] [Medline: 28545640]

17. Vader JM, LaRue SJ, Stevens SR, Mentz RJ, DeVore AD, Lala A, et al. Timing and Causes of Readmission After Acute Heart Failure Hospitalization-Insights From the Heart Failure Network Trials. J Card Fail 2016 Nov;22(11):875-883 [FREE Full text] [doi: 10.1016/j.cardfail.2016.04.014] [Medline: 27133201]

\author{
Abbreviations \\ AUC: area under the receiver operating characteristics curve \\ BNP: B-type natriuretic peptide \\ bpm: beats per minute \\ EMA: ecological momentary assessment \\ HF: heart failure \\ HR: heart rate \\ mHealth: mobile health \\ PND: paroxysmal nocturnal dyspnea \\ YI: Youden index
}

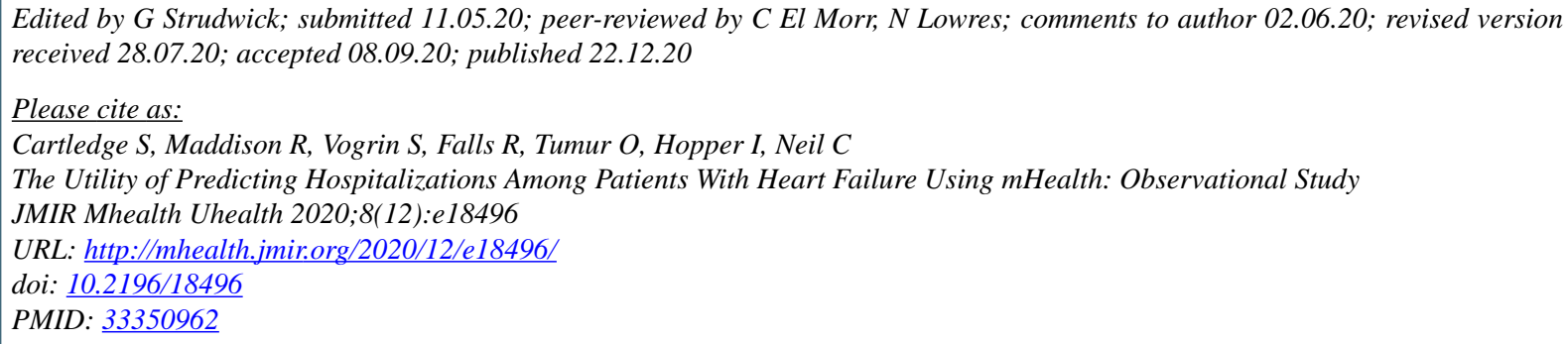

(C) Susie Cartledge, Ralph Maddison, Sara Vogrin, Roman Falls, Odgerel Tumur, Ingrid Hopper, Christopher Neil. Originally published in JMIR mHealth and uHealth (http://mhealth.jmir.org), 22.12.2020. This is an open-access article distributed under the terms of the Creative Commons Attribution License (https://creativecommons.org/licenses/by/4.0/), which permits unrestricted use, distribution, and reproduction in any medium, provided the original work, first published in JMIR mHealth and uHealth, is properly cited. The complete bibliographic information, a link to the original publication on http://mhealth.jmir.org/, as well as this copyright and license information must be included. 